\title{
APPROXIMATING FIXED POINTS OF $\lambda$-FIRMLY NONEXPANSIVE MAPPINGS IN BANACH SPACES
}

\author{
GANG-EUN KIM
}

(Received 2 September 1997)

\begin{abstract}
We study the convergence of the Ishikawa iteration methods to fixed points for the result of Smarzewski (1991). Our theorems also improve recent theorems due to Sharma and Sahu (1996).
\end{abstract}

Keywords and phrases. $\lambda$-firmly nonexpansive mapping, fixed point, Opial's condition, Fréchet differentiable norm.

2000 Mathematics Subject Classification. Primary 46B20; Secondary 47H10.

1. Introduction. Let $E$ be a real Banach space and let $C$ be a nonempty closed convex subset of $E$. Then a mapping $T$ of $C$ into itself is called nonexpansive if $\|T x-T y\| \leq$ $\|x-y\|$ for all $x, y \in C$. A mapping $T$ of $C$ into itself is called $\lambda$-firmly nonexpansive if there exists $\lambda \in(0,1)$ such that

$$
\|T x-T y\| \leq\|(1-\lambda)(x-y)+\lambda(T x-T y)\| \quad \forall x, y \in C .
$$

It is clear that every $\lambda$-firmly nonexpansive mapping is nonexpansive. For a mapping $T$ of $C$ into itself, we consider the following iteration scheme: $x_{1} \in C$,

$$
x_{n+1}=\alpha_{n} T\left[\beta_{n} T x_{n}+\left(1-\beta_{n}\right) x_{n}\right]+\left(1-\alpha_{n}\right) x_{n} \quad \forall n \geq 1,
$$

where $\left\{\alpha_{n}\right\}$ and $\left\{\beta_{n}\right\}$ are real sequences in $[0,1]$. Such an iteration scheme was introduced by Ishikawa [5]; see also Mann iteration scheme (corresponding to the choice $\beta_{n}=0$ for all $n \in N$ ) [6]. Now let $C$ be a nonempty convex subset of a Banach space $E$, and let $T, S$ be mappings of $C$ into itself. Then, for an $x_{1} \in C$, we consider the iterates $\left\{x_{n}\right\}$ defined by

$$
\begin{gathered}
x_{n+1}=\alpha_{n} T y_{n}+\left(1-\alpha_{n}\right) S x_{n}, \\
y_{n}=\beta_{n} T x_{n}+\left(1-\beta_{n}\right) x_{n} \quad \forall n \geq 1,
\end{gathered}
$$

where $\alpha_{n}$ and $\beta_{n}$ satisfy $0<a \leq \alpha_{n}, \beta_{n} \leq b<1$. If $S=I$, the identity mapping, the iterates (1.3) are reduced to the above special case due to Ishikawa [5]. In 1991, Smarzewski [10] proved the following result: let $E$ be a uniformly convex Banach space and let $C=\bigcup_{i=1}^{n} C_{i}$ be a union of nonempty bounded closed convex subsets $C_{i}$ of $E$ and suppose $T: C \rightarrow C$ is $\lambda$-firmly nonexpansive for some $\lambda \in(0,1)$. Then $T$ has a fixed point in $C$. The result above is no longer true if $T$ is merely nonexpansive, even in one-dimensional space; see [10]. Recently, Sharma and Sahu [9] studied the 
convergence of the Mann and Ishikawa iteration methods to fixed points for the result of Smarzewski [10].

In this paper, we first show that the iterates $\left\{x_{n}\right\}$ and $\left\{y_{n}\right\}$ defined by (1.3) converge weakly to the same common fixed point of $T$ and $S$ when $E$ is a uniformly convex Banach space with Opial's condition or Fréchet differentiable norm. Next, we show that the iterates $\left\{x_{n}\right\}$ defined by (1.2) converge weakly to a fixed point of $T$ when $E$ is a uniformly convex Banach space with Opial's condition. Finally, we show that if $E$ is uniform convex and if the ranges of $T$ are contained in a compact subset of $C$, the iterates $\left\{x_{n}\right\}$ defined by (1.2) converge strongly to a fixed point of $T$. This paper also improves recent theorems due to Sharma and Sahu [9] using ideas of TakahashiKim [12].

2. Preliminaries. Throughout this paper, we denote by $E$ and $E^{*}$ a real Banach space and the dual space of $E$, respectively. The value of $x^{*} \in E^{*}$ at $x \in E$ is denoted by $\left\langle x, x^{*}\right\rangle$. Let $C$ be a nonempty closed convex subset of $E$ and let $T$ be a mapping from $C$ into itself. Then we denote by $F(T)$ the set of all fixed points of $T$, i.e., $F(T)=$ $\{x \in C: T x=x\}$. We also denote by $\mathbb{N}$ the set of all natural numbers and by $\mathbb{R}$ and $\mathbb{R}^{+}$ the sets of all real numbers and all nonnegative real numbers, respectively. $\overline{\mathrm{Co}} A$ means the closure of the convex hull of $A$. A Banach space $E$ is called uniformly convex if for each $\epsilon>0$ there is a $\delta>0$ such that for $x, y \in E$ with $\|x\|,\|y\| \leq 1$ and $\|x-y\| \geq \epsilon$, $\|x+y\| \leq 2(1-\delta)$ holds. When $\left\{x_{n}\right\}$ is a sequence in $E$, then $x_{n} \rightarrow x$ (resp., $x_{n} \rightarrow x$, $x_{n} \stackrel{*}{\rightarrow} x$ ) denote strong (resp., weak, weak ${ }^{*}$ ) convergence of the sequence $\left\{x_{n}\right\}$ to $x$. A Banach space $E$ is said to satisfy Opial's condition [7] if for any sequence $\left\{x_{n}\right\}$ in $E$, $x_{n} \rightarrow x$ implies that

$$
\limsup _{n \rightarrow \infty}\left\|x_{n}-x\right\|<\limsup _{n \rightarrow \infty}\left\|x_{n}-y\right\| \quad \forall y \in E \text { with } y \neq x .
$$

If $I-T$ is demiclosed at zero [1], i.e., for any sequence $\left\{x_{n}\right\}$ in $C$, the conditions $x_{n} \rightarrow x$ weakly and $x_{n}-T x_{n} \rightarrow 0$ strongly imply $x-T x=0$. With each $x \in E$, we associate the set

$$
J_{\phi}(x)=\left\{x^{*} \in E^{*}:\left\langle x, x^{*}\right\rangle=\|x\|\left\|x^{*}\right\| \text { and }\left\|x^{*}\right\|=\phi(\|x\|)\right\},
$$

where $\phi: \mathbb{R}^{+} \rightarrow \mathbb{R}^{+}$is a continuous and strictly increasing function with $\phi(0)=0$ and $\phi(\infty)=\infty$. Then $J_{\phi}: E \rightarrow 2^{E^{*}}$ is said to be the duality mapping. Suppose that $J_{\phi}$ is single-valued. Then $J_{\phi}$ is said to be weakly sequentially continuous if for each $\left\{x_{n}\right\} \in E$ with $x_{n} \rightarrow x$, then $J_{\phi}\left(x_{n}\right) \stackrel{*}{\rightarrow} J_{\phi}(x)$. For abbreviation, we set $J:=J_{\phi}$. In all our proofs we assume, without loss of generality, that $J$ is normalized. We know that if $E$ admits a weakly sequentially continuous duality mapping, then $E$ satisfies Opial's condition; see [4]. Let $S(E)=\{x \in E:\|x\|=1\}$. Then the norm of $E$ is said to be Gâteaux differentiable (and $E$ is said to be smooth) if

$$
\lim _{t \rightarrow 0} \frac{\|x+t y\|-\|x\|}{t}
$$

exists for each $x$ and $y$ in $S(E)$. It is also said to be Fréchet differentiable if, for each $x \in S(E)$, the limit (2.3) is attained uniformly in $y \in S(E)$. All Hilbert spaces and 
$l^{p}(1<p<\infty)$ satisfy Opial's condition, while $L^{p}$ with $1<p \neq 2<\infty$ do not. It is well known that if $E$ is smooth, then the duality mapping $J$ is single-valued and strongweak* $^{*}$ continuous; for more details, see [2] or [11].

3. Convergence theorems. We first begin with the following.

LEMMA 3.1 (see [8]). Let $E$ be a uniformly convex Banach space, $0<b \leq t_{n} \leq c<1$ for all $n \geq 1$, and $a \geq 0$. Suppose that $\left\{x_{n}\right\}_{n=1}^{\infty}$ and $\left\{y_{n}\right\}_{n=1}^{\infty}$ are sequences of $E$ such that $\limsup _{n \rightarrow \infty}\left\|x_{n}\right\| \leq a$, $\limsup _{n \rightarrow \infty}\left\|y_{n}\right\| \leq a$, and $\lim _{n \rightarrow \infty}\left\|t_{n} x_{n}+\left(1-t_{n}\right) y_{n}\right\|=a$. Then $\lim _{n \rightarrow \infty}\left\|x_{n}-y_{n}\right\|=0$.

Using Lemma 3.1, we have the following.

LEMMA 3.2. Let $C=\bigcup_{i=1}^{n} C_{i}$ be a union of nonempty closed convex subsets $C_{i}$ of a uniformly convex Banach space $E$ and let $T, S: C \rightarrow C$ be $\lambda$-firmly nonexpansive for some $\lambda \in(0,1)$ and $t T(s T x+(1-s) x)+(1-t) S x \in C$ for all $x \in C$ and $s, t \in(0,1)$. Then $F(T) \cap F(S)$ is nonempty if and only if the iterates $\left\{x_{n}\right\}$ defined by (1.3) is bounded, $\left\{x_{n}-T x_{n}\right\}$ and $\left\{x_{n}-S x_{n}\right\}$ converge strongly to zero as $n \rightarrow \infty$.

Proof. Let $w$ be a common fixed point of $T$ and $S$. Since $T$ and $S$ are $\lambda$-firmly nonexpansive for some $\lambda \in(0,1)$, it is easy to check that $\left\|x_{n+1}-w\right\| \leq\left\|x_{n}-w\right\|$ for all $n \geq 1$. So, $\left\{x_{n}\right\}$ is bounded and $\lim _{n \rightarrow \infty}\left\|x_{n}-w\right\|$ exists. Put $c=\lim _{n \rightarrow \infty}\left\|x_{n}-w\right\|$. Since $T$ is $\lambda$-firmly nonexpansive for some $\lambda \in(0,1)$, we obtain

$$
\begin{aligned}
\left\|T y_{n}-w\right\| & \leq\left\|(1-\lambda)\left(y_{n}-w\right)+\lambda\left(T y_{n}-w\right)\right\| \\
& \leq(1-\lambda)\left\|y_{n}-w\right\|+\lambda\left\|T y_{n}-w\right\|,
\end{aligned}
$$

and thus $\left\|T y_{n}-w\right\| \leq\left\|y_{n}-w\right\|$. Taking limsup $\operatorname{sum}_{n \rightarrow \infty}$ in both sides, we obtain

$$
\limsup _{n \rightarrow \infty}\left\|T y_{n}-w\right\| \leq \limsup _{n \rightarrow \infty}\left\|y_{n}-w\right\| \leq \limsup _{n \rightarrow \infty}\left\|x_{n}-w\right\|=c \text {. }
$$

Furthermore, since

$$
\lim _{n \rightarrow \infty}\left\|\alpha_{n}\left(T y_{n}-w\right)+\left(1-\alpha_{n}\right)\left(S x_{n}-w\right)\right\|=\lim _{n \rightarrow \infty}\left\|x_{n+1}-w\right\|=c,
$$

by Lemma 3.1, we have $\lim _{n \rightarrow \infty}\left\|T y_{n}-S x_{n}\right\|=0$. Since

$$
\begin{aligned}
\left\|x_{n+1}-w\right\| & \leq \alpha_{n}\left\|T y_{n}-w\right\|+\left(1-\alpha_{n}\right)\left\|x_{n}-w\right\| \\
& \leq \alpha_{n}\left\|y_{n}-w\right\|+\left(1-\alpha_{n}\right)\left\|x_{n}-w\right\|,
\end{aligned}
$$

we have

$$
\frac{\left\|x_{n+1}-w\right\|-\left\|x_{n}-w\right\|}{\alpha_{n}} \leq\left\|y_{n}-w\right\|-\left\|x_{n}-w\right\| .
$$

Since $\left\{\alpha_{n}\right\}$ is assumed to be bounded away from zero, we obtain

$$
c \leq \liminf _{n \rightarrow \infty}\left\|y_{n}-w\right\| .
$$

Since $\left\|y_{n}-w\right\| \leq\left\|x_{n}-w\right\|$ for all $n \geq 1$, we have

$$
c=\lim _{n \rightarrow \infty}\left\|y_{n}-w\right\|=\lim _{n \rightarrow \infty}\left\|\beta_{n}\left(T x_{n}-w\right)+\left(1-\beta_{n}\right)\left(x_{n}-w\right)\right\| .
$$


By Lemma 3.1, we have $\lim _{n \rightarrow \infty}\left\|T x_{n}-x_{n}\right\|=0$. Since

$$
\begin{aligned}
\left\|x_{n}-S x_{n}\right\| & \leq\left\|x_{n}-T x_{n}\right\|+\left\|T x_{n}-T y_{n}\right\|+\left\|T y_{n}-S x_{n}\right\| \\
& \leq\left(1+\beta_{n}\right)\left\|x_{n}-T x_{n}\right\|+\left\|T y_{n}-S x_{n}\right\|,
\end{aligned}
$$

we have $x_{n}-S x_{n} \rightarrow 0$ as $n \rightarrow \infty$.

Conversely, suppose that $\left\{x_{n}\right\}$ is bounded, $\left\{x_{n}-T x_{n}\right\}$ and $\left\{x_{n}-S x_{n}\right\}$ converge strongly to zero as $n \rightarrow \infty$. Then we can consider a real-valued function $g$ on $C$ given by

$$
g(v)=\limsup _{n \rightarrow \infty}\left\|x_{n}-v\right\| \quad \text { for each } v \in C .
$$

By [11], we know that $g: C \rightarrow \mathbb{R}$ is continuous and convex. Further, if $\left\|v_{n}\right\| \rightarrow \infty$, then $g\left(v_{n}\right) \rightarrow \infty$. So, we have an element $v_{0} \in C$ such that $g\left(v_{0}\right)=r=\min _{v \in C} g(v)$. Set $M=\left\{v_{0} \in C: r=g\left(v_{0}\right)\right\}$. Then $M$ is bounded, closed, and convex. Further, $M$ is invariant under $T$. In fact, let $z \in M$. Then, for some $\lambda \in(0,1)$, we have

$$
\begin{aligned}
\limsup _{n \rightarrow \infty}\left\|T x_{n}-T z\right\| & \leq \limsup _{n \rightarrow \infty}\left\|(1-\lambda)\left(x_{n}-z\right)+\lambda\left(T x_{n}-T z\right)\right\| \\
& \leq(1-\lambda) \limsup _{n \rightarrow \infty}\left\|x_{n}-z\right\|+\lambda \limsup _{n \rightarrow \infty}\left\|T x_{n}-T z\right\|
\end{aligned}
$$

and thus

$$
\limsup _{n \rightarrow \infty}\left\|x_{n}-T z\right\|=\limsup _{n \rightarrow \infty}\left\|T x_{n}-T z\right\| \leq \limsup _{n \rightarrow \infty}\left\|x_{n}-z\right\| .
$$

Hence $T z \in M$. Similarly, $M$ is invariant under $S$. Since $E$ is uniformly convex and hence $M$ consists of one point, we have a common fixed point of $T$ and $S$ in $M$; see [13].

REMARK 3.3. In Lemma 3.2, if $F(T) \cap F(S) \neq \varnothing$, then we furthermore see that $\left\{y_{n}-\right.$ $\left.T y_{n}\right\}$ and $\left\{y_{n}-S y_{n}\right\}$ converge strongly to zero as $n \rightarrow \infty$.

We first consider the following weak convergence of $\lambda$-firmly nonexpansive mappings in a Banach space.

THEOREM 3.4. Let E be a uniformly convex Banach space satisfying Opial's condition and let $C=\bigcup_{i=1}^{n} C_{i}$ be a union of nonempty closed convex subsets $C_{i}$ of $E$ and let $T$, $S: C \rightarrow C$ be $\lambda$-firmly nonexpansive for some $\lambda \in(0,1)$ with a common fixed point and $t T(s T x+(1-s) x)+(1-t) S x \in C$ for all $x \in C$ and $s, t \in(0,1)$. Then the iterates $\left\{x_{n}\right\}$ and $\left\{y_{n}\right\}$ defined by (1.3) converge weakly to a common fixed point of $T$ and $S$. Further, the two $w$-limits of $\left\{x_{n}\right\}$ and $\left\{y_{n}\right\}$ coincide.

Proof. Let $z$ be a common fixed point of $T$ and $S$. Then, as in the proof of Lemma 3.2, we have $\lim _{n \rightarrow \infty}\left\|x_{n}-z\right\|$ exists. Let $z_{1}$ and $z_{2}$ be two weak subsequential limits of the sequence $\left\{x_{n}\right\}$. We claim that the conditions $x_{n_{i}}-z_{1}$ and $x_{n_{j}} \rightarrow z_{2}$ imply $z_{1}=z_{2} \in F(T) \cap F(S)$. We first show that $z_{1}, z_{2} \in F(T)$. In fact, if $T z_{1} \neq z_{1}$, then, by Opial's condition, we have $\limsup _{i \rightarrow \infty}\left\|x_{n_{i}}-z_{1}\right\|<\limsup \sup _{i \rightarrow \infty}\left\|x_{n_{i}}-T z_{1}\right\|$. Since $T$ is $\lambda$-firmly nonexpansive for some $\lambda \in(0,1)$, we obtain

$$
\begin{aligned}
\limsup _{i \rightarrow \infty}\left\|T x_{n_{i}}-T z_{1}\right\| & \leq \underset{i \rightarrow \infty}{\limsup }\left\|(1-\lambda)\left(x_{n_{i}}-z_{1}\right)+\lambda\left(T x_{n_{i}}-T z_{1}\right)\right\| \\
& \leq(1-\lambda) \limsup _{i \rightarrow \infty}\left\|x_{n_{i}}-z_{1}\right\|+\lambda \underset{i \rightarrow \infty}{\limsup }\left\|T x_{n_{i}}-T z_{1}\right\| .
\end{aligned}
$$


By Lemma 3.2, we have

$$
\underset{i \rightarrow \infty}{\limsup }\left\|x_{n_{i}}-T z_{1}\right\| \leq \limsup _{i \rightarrow \infty}\left\|x_{n_{i}}-z_{1}\right\| .
$$

This is a contradiction. Hence we have $T z_{1}=z_{1}$. Similarly, we have $z_{2} \in F(T)$. Next, we show $z_{1}=z_{2}$. If not, by Opial's condition,

$$
\begin{aligned}
\lim _{n \rightarrow \infty}\left\|x_{n}-z_{1}\right\| & =\lim _{i \rightarrow \infty}\left\|x_{n_{i}}-z_{1}\right\|<\lim _{i \rightarrow \infty}\left\|x_{n_{i}}-z_{2}\right\| \\
& =\lim _{n \rightarrow \infty}\left\|x_{n}-z_{2}\right\|=\lim _{j \rightarrow \infty}\left\|x_{n_{j}}-z_{2}\right\| \\
& <\lim _{j \rightarrow \infty}\left\|x_{n_{j}}-z_{1}\right\|=\lim _{n \rightarrow \infty}\left\|x_{n}-z_{1}\right\| .
\end{aligned}
$$

This is a contradiction. Hence we have $z_{1}=z_{2}$. By using the same method as above, we have $z_{1}=z_{2} \in F(S)$. This implies that $\left\{x_{n}\right\}$ converges weakly to a common fixed point of $T$ and $S$. As in the proof of Lemma 3.2, we have $\lim _{n \rightarrow \infty}\left\|y_{n}-z\right\|$ exists. Let $y_{n_{i}}-w_{1}$ and $y_{n_{j}}-w_{2}$. Then, by using the same method as above, we obtain $w_{1}=w_{2} \in F(T) \cap F(S)$. Further, since $\left\|x_{n}-y_{n}\right\|=\beta_{n}\left\|x_{n}-T x_{n}\right\| \rightarrow 0$ as $n \rightarrow \infty$, we readily see that two $w$-limits of $\left\{x_{n}\right\}$ and $\left\{y_{n}\right\}$ coincide.

THEOREM 3.5. Let $E$ be a uniformly convex Banach space with a Fréchet differentiable norm. Let $C=\bigcup_{i=1}^{n} C_{i}$ be a union of nonempty closed convex subsets $C_{i}$ of $E$ and let $T, S: C \rightarrow C$ be $\lambda$-firmly nonexpansive for some $\lambda \in(0,1)$ with a common fixed point, and let $I-T, I-S$ be demiclosed at zero and $t T(s T x+(1-s) x)+(1-t) S x \in C$ for all $x \in C$ and $s, t \in(0,1)$. Then the iterates $\left\{x_{n}\right\}$ and $\left\{y_{n}\right\}$ defined by (1.3) converge weakly to a common fixed point of $T$ and $S$. Further, the two $w$-limits of $\left\{x_{n}\right\}$ and $\left\{y_{n}\right\}$ coincide.

Proof. Since $F(T) \cap F(S)$ is nonempty, it follows from Lemma 3.2 that $\left\{x_{n}\right\}$ is bounded, $\left\{x_{n}-T x_{n}\right\}$ and $\left\{x_{n}-S x_{n}\right\}$ converge strongly to zero as $n \rightarrow \infty$. There exists a subsequence $\left\{x_{n_{i}}\right\}$ of $\left\{x_{n}\right\}$ and a point $z \in C$ such that $x_{n_{i}}-z$. Since $I-T$ and $I-S$ are demiclosed at zero, we obtain $z \in F(T) \cap F(S)$. For $y, z \in F(T) \cap F(S)$, as in the proof of Lemma 2 [12], we have $\lim _{n \rightarrow \infty}\left\langle x_{n}, J(y-z)\right\rangle$ exists. To prove Theorem 3.5, assume $x_{n_{i}}-z_{1}$ and $x_{n_{j}}-z_{2}$. Then, for $y, z \in F(T) \cap F(S)$, we have

$$
\begin{aligned}
\left\langle z_{1}, J(y-z)\right\rangle & =\lim _{i \rightarrow \infty}\left\langle x_{n_{i}}, J(y-z)\right\rangle=\lim _{n \rightarrow \infty}\left\langle x_{n}, J(y-z)\right\rangle \\
& =\lim _{j \rightarrow \infty}\left\langle x_{n_{j}}, J(y-z)\right\rangle=\left\langle z_{2}, J(y-z)\right\rangle .
\end{aligned}
$$

Setting $y=z_{1}$ and $z=z_{2}$, we obtain $\left\langle z_{1}-z_{2}, J\left(z_{1}-z_{2}\right)\right\rangle=0$ and hence $z_{1}=z_{2}$. This implies that $\left\{x_{n}\right\}$ converges weakly to a common fixed point of $T$ and $S$. By using the same method as above, $\left\{y_{n}\right\}$ converges weakly to a common fixed point of $T$ and $S$. Further, since $x_{n}-y_{n} \rightarrow 0$ as $n \rightarrow \infty$, the remaining part of the proof is trivial.

THEOREM 3.6. Let $E$ be a uniformly convex Banach space satisfying Opial's condition, and let $C=\bigcup_{i=1}^{n} C_{i}$ be a union of nonempty bounded closed convex subsets $C_{i}$ of $E$ and let $T: C \rightarrow C$ be $\lambda$-firmly nonexpansive for some $\lambda \in(0,1)$ and $t T(s T x+(1-$ $s) x)+(1-t) x \in C$ for all $x \in C$ and $s, t \in(0,1)$. Then for any initial data $x_{1}$ in $C$, the iterates $\left\{x_{n}\right\}$ defined by (1.2), where $\left\{\alpha_{n}\right\}$ and $\left\{\beta_{n}\right\}$ are chosen so that $\alpha_{n} \in[a, b]$ and 
$\beta_{n} \in[0, b]$ or $\alpha_{n} \in[a, 1]$ and $\beta_{n} \in[a, b]$ for some $a, b$ with $0<a \leq b<1$, converge weakly to a fixed point of $T$.

Proof. The existence of a fixed point follows from Smarzewski [10]. Let $w$ be a fixed point of $T$. Then, as in the proof of Lemma 3.2, we have $\lim _{n \rightarrow \infty}\left\|x_{n}-w\right\|$ exists. Put $c=\lim _{n \rightarrow \infty}\left\|x_{n}-w\right\|$. Since $T$ is $\lambda$-firmly nonexpansive for some $\lambda \in(0,1)$, we obtain

$$
\begin{aligned}
\left\|T y_{n}-w\right\| & \leq\left\|(1-\lambda)\left(y_{n}-w\right)+\lambda\left(T y_{n}-w\right)\right\| \\
& \leq(1-\lambda)\left\|y_{n}-w\right\|+\lambda\left\|T y_{n}-w\right\|
\end{aligned}
$$

and thus $\left\|T y_{n}-w\right\| \leq\left\|y_{n}-w\right\|$. Taking limsup $\operatorname{sum}_{n \rightarrow \infty}$ in both sides, we obtain

$$
\limsup _{n \rightarrow \infty}\left\|T y_{n}-w\right\| \leq \limsup _{n \rightarrow \infty}\left\|x_{n}-w\right\|=c .
$$

Further, we have

$$
\lim _{n \rightarrow \infty}\left\|\alpha_{n}\left(T y_{n}-w\right)+\left(1-\alpha_{n}\right)\left(x_{n}-w\right)\right\|=\lim _{n \rightarrow \infty}\left\|x_{n+1}-w\right\|=c .
$$

If $0<a \leq \alpha_{n} \leq b<1$ and $0 \leq \beta_{n} \leq b<1$, by Lemma 3.1, we have $\lim _{n \rightarrow \infty}\left\|T y_{n}-x_{n}\right\|=$ 0 . Since

$$
\begin{aligned}
\left\|T x_{n}-x_{n}\right\| & \leq\left\|T x_{n}-T y_{n}\right\|+\left\|T y_{n}-x_{n}\right\| \\
& \leq\left\|x_{n}-y_{n}\right\|+\left\|T y_{n}-x_{n}\right\| \\
& \leq \beta_{n}\left\|T x_{n}-x_{n}\right\|+\left\|T y_{n}-x_{n}\right\|,
\end{aligned}
$$

we obtain

$$
(1-b)\left\|T x_{n}-x_{n}\right\| \leq\left(1-\beta_{n}\right)\left\|T x_{n}-x_{n}\right\| \leq\left\|T y_{n}-x_{n}\right\| .
$$

Therefore $\left\|x_{n}-T x_{n}\right\| \rightarrow 0$ as $n \rightarrow \infty$. On the other hand, we have, for all $n \geq 1$,

$$
\begin{aligned}
\left\|x_{n+1}-w\right\| & \leq \alpha_{n}\left\|T y_{n}-w\right\|+\left(1-\alpha_{n}\right)\left\|x_{n}-w\right\| \\
& \leq \alpha_{n}\left\|y_{n}-w\right\|+\left(1-\alpha_{n}\right)\left\|x_{n}-w\right\|
\end{aligned}
$$

and hence

$$
\frac{\left\|x_{n+1}-w\right\|-\left\|x_{n}-w\right\|}{\alpha_{n}} \leq\left\|y_{n}-w\right\|-\left\|x_{n}-w\right\| .
$$

If $0<a \leq \alpha_{n} \leq 1$ and $0<a \leq \beta_{n} \leq b<1$, we obtain

$$
c \leq \liminf _{n \rightarrow \infty}\left\|y_{n}-w\right\| .
$$

Since $\left\|y_{n}-w\right\| \leq\left\|x_{n}-w\right\|$ for all $n \geq 1$, we obtain

$$
c=\lim _{n \rightarrow \infty}\left\|y_{n}-w\right\|=\lim _{n \rightarrow \infty}\left\|\beta_{n}\left(T x_{n}-w\right)+\left(1-\beta_{n}\right)\left(x_{n}-w\right)\right\| .
$$

By Lemma 3.1, we have $\lim _{n \rightarrow \infty}\left\|T x_{n}-x_{n}\right\|=0$. As in the proof of Theorem 3.4, the result follows.

COROLlary 3.7. Let $E$ be a uniformly convex Banach space possessing a weakly sequentially continuous duality mapping and let $C=\bigcup_{i=1}^{n} C_{i}$ be a union of nonempty bounded closed convex subsets $C_{i}$ of $E$ and let $T: C \rightarrow C$ be a $\lambda$-firmly nonexpansive for some $\lambda \in(0,1)$ and let $I-T$ be demiclosed at zero and $t T x+(1-t) x \in C$ for all $x \in C$ and $t \in(0,1)$. Let $\left\{\alpha_{n}\right\}$ be a real sequence satisfying $0<a \leq \alpha_{n} \leq b<1$ for all $n \in \mathbb{N}$. 
Pick $x_{1} \in C$ and define $x_{n+1}=\alpha_{n} T x_{n}+\left(1-\alpha_{n}\right) x_{n}$ for all $n \in N$. Then $\left\{x_{n}\right\}$ converges weakly to a fixed point of $T$.

COROLLARY 3.8. Let $E$ be a uniformly convex Banach space possessing a weakly sequentially continuous duality mapping and let $C=\bigcup_{i=1}^{n} C_{i}$ be a union of nonempty bounded closed convex subsets $C_{i}$ of $E$ and let $T: C \rightarrow C$ be $\lambda$-firmly nonexpansive for some $\lambda \in(0,1)$ and let $I-T$ be demiclosed at zero and $t T(s T x+(1-s) x)+(1-t) x \in$ $C$ for all $x \in C$ and $s, t \in(0,1)$. Let $\left\{\alpha_{n}\right\}$ and $\left\{\beta_{n}\right\}$ be two sequence real sequence satisfying $0<a \leq \alpha_{n} \leq b<1$ and $0<c \leq \beta_{n} \leq d<1$ for all $n \in N$. Pick $x_{1} \in C$ and the iterates $\left\{x_{n}\right\}$ defined by (1.2). Then $\left\{x_{n}\right\}$ converges weakly to a fixed point of $T$.

Next, we consider a strong convergence of $\lambda$-firmly nonexpansive mapping in a Banach space.

THEOREM 3.9. Let $E$ be a uniformly convex Banach space and let $C=\bigcup_{i=1}^{n} C_{i}$ be a union of nonempty bounded closed convex subsets $C_{i}$ of $E$ with $C_{i} \subseteq C_{i+1}$. Suppose that $T: C \rightarrow C$ is $\lambda$-firmly nonexpansive for some $\lambda \in(0,1)$ such that $T(C)$ is contained in a compact subset of $C$. Then for any initial data $x_{1}$ in $C$, the iterates $\left\{x_{n}\right\}$ defined by (1.2), where $\left\{\alpha_{n}\right\}$ and $\left\{\beta_{n}\right\}$ are chosen so that $\alpha_{n} \in[a, b]$ and $\beta_{n} \in[0, b]$ or $\alpha_{n} \in[a, 1]$ and $\beta_{n} \in[a, b]$ for some $a, b$ with $0<a \leq b<1$, converge strongly to a fixed point of $T$.

Proof. Note that $\left\{x_{n}\right\}$ is well defined. The existence of a fixed point follows from Smarzewski [10]. By Mazur's theorem [3], $\overline{\mathrm{co}}\left(\left\{x_{1}\right\} \cup T(C)\right)$ is a compact subset of $C$ containing $\left\{x_{n}\right\}$. There exist a subsequence $\left\{x_{m}\right\}$ of the sequence $\left\{x_{n}\right\}$ and a point $z \in C$ such that $x_{m} \rightarrow z$. As in the proof of Theorem 3.6, $\left\{x_{n}-T x_{n}\right\}$ converges strongly to zero as $n \rightarrow \infty$. Since $T$ is $\lambda$-firmly nonexpansive for some $\lambda \in(0,1)$, we obtain

$$
\begin{aligned}
\|z-T z\| & \leq\left\|z-x_{m}\right\|+\left\|x_{m}-T x_{m}\right\|+\left\|T x_{m}-T z\right\| \\
& \leq 2\left\|z-x_{m}\right\|+\left\|x_{m}-T x_{m}\right\| \longrightarrow 0 \text { as } m \longrightarrow \infty .
\end{aligned}
$$

Hence $T z=z$. As in the proof of Lemma 3.2, we have $\lim _{n \rightarrow \infty}\left\|x_{n}-z\right\|$ exists. Hence we have $\lim _{n \rightarrow \infty}\left\|x_{n}-z\right\|=0$.

REMARK 3.10. In Theorem 3.9, if $T, S: C \rightarrow C$ are $\lambda$-firmly nonexpansive for some $\lambda \in(0,1)$ such that $T(C)$ and $S(C)$ are contained in a compact subset of $C$ and $F(T) \cap$ $F(S) \neq \varnothing$, then the iterates $\left\{x_{n}\right\}$ and $\left\{y_{n}\right\}$ defined by (1.3) converge strongly to the same common fixed point of $T$ and $S$.

\section{REFERENCES}

[1] F. E. Browder, Nonlinear operators and nonlinear equations of evolution in Banach spaces, Nonlinear Functional Analysis (Proc. Sympos. Pure Math., Vol. XVIII, Part 2, Chicago, Ill., 1968) (Providence, R.I.), Amer. Math. Soc., 1976, pp. 1-308. MR 53\#8982. Zbl 327.47022 .

[2] J. Diestel, Geometry of Banach Spaces-Selected Topics, Lecture Notes in Math., vol. 485, Springer-Verlag, Berlin, 1975. MR 57\#1079. Zbl 307.46009.

[3] N. Dunford and J. T. Schwartz, Linear Operators. I. General Theory, Interscience Publishers, Inc., New York, 1958. MR 22\#8302. Zbl 084.10402.

[4] J. P. Gossez and E. Lami Dozo, Some geometric properties related to the fixed point theory for nonexpansive mappings, Pacific J. Math. 40 (1972), 565-573. MR $46 \# 9815$. Zbl 231.47027. 
[5] S. Ishikawa, Fixed points by a new iteration method, Proc. Amer. Math. Soc. 44 (1974), 147-150. MR 49\#1243. Zbl 286.47036.

[6] W. R. Mann, Mean value methods in iteration, Proc. Amer. Math. Soc. 4 (1953), 506-510. MR 14,988f. Zbl 050.11603.

[7] Z. Opial, Weak convergence of the sequence of successive approximations for nonexpansive mappings, Bull. Amer. Math. Soc. 73 (1967), 591-597. MR 35\#2183. Zbl 179.19902.

[8] J. Schu, Weak and strong convergence to fixed points of asymptotically nonexpansive mappings, Bull. Austral. Math. Soc. 43 (1991), no. 1, 153-159. MR 91k:47136. Zbl 709.47051.

[9] B. K. Sharma and D. R. Sahu, Fixed point approximation for $\lambda$-firmly nonexpansive mappings, Bull. Calcutta Math. Soc. 88 (1996), no. 4, 285-290. MR 98h:47079. Zbl 881.47042.

[10] R. Smarzewski, On firmly nonexpansive mappings, Proc. Amer. Math. Soc. 113 (1991), no. 3, 723-725. MR 92b:47089. Zbl 734.47039.

[11] W. Takahashi, Nonlinear Functional Analysis, Kindaikagaku, Tokyo, 1988 (Japanese).

[12] W. Takahashi and G. E. Kim, Approximating fixed points of nonexpansive mappings in Banach spaces, Math. Japon. 48 (1998), no. 1, 1-9. MR 2000b:47127. Zbl 913.47056.

[13] E. Zeidler, Nonlinear Functional Analysis and its Applications. I, Springer-Verlag, New York, 1986. MR 87f:47083. Zbl 583.47050.

Gang-Eun Kim: Department of Applied Mathematics, Pukyong National University, PUSAN 608-737, KOREA 


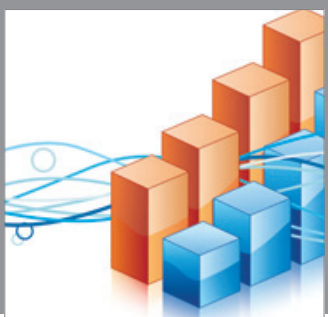

Advances in

Operations Research

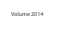

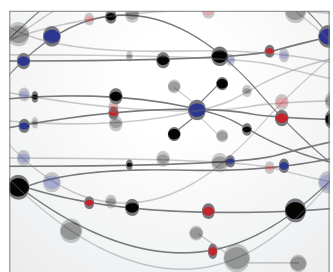

\section{The Scientific} World Journal
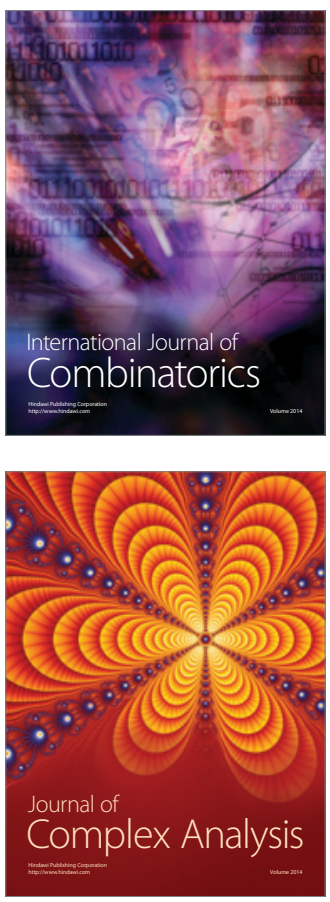

International Journal of

Mathematics and

Mathematical

Sciences
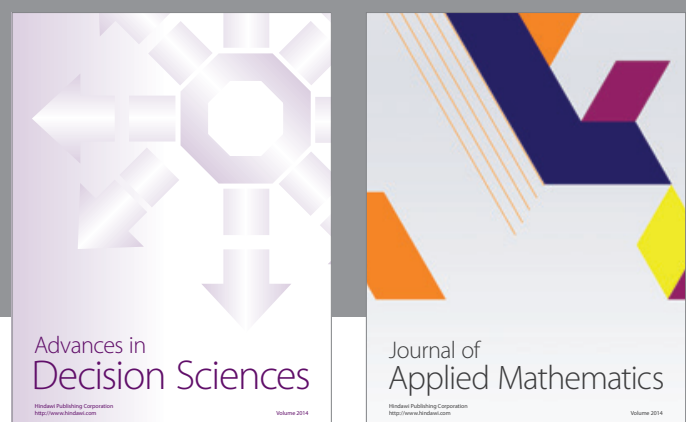

Journal of

Applied Mathematics
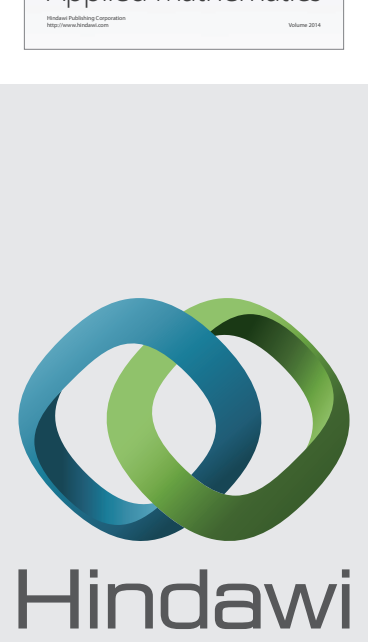

Submit your manuscripts at http://www.hindawi.com
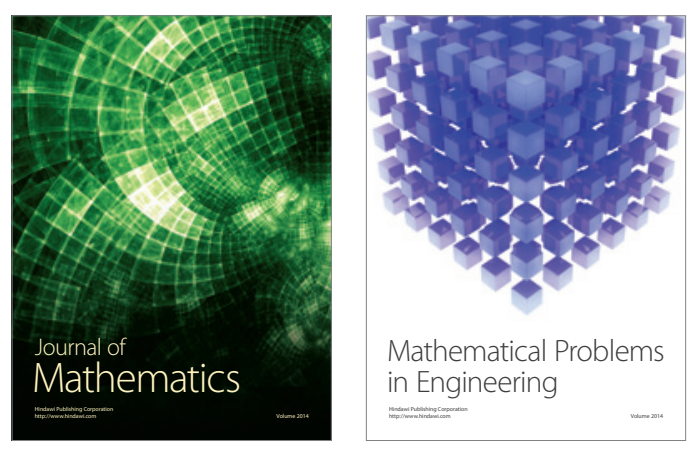

Mathematical Problems in Engineering
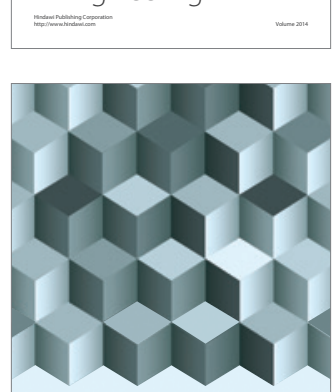

Journal of

Function Spaces
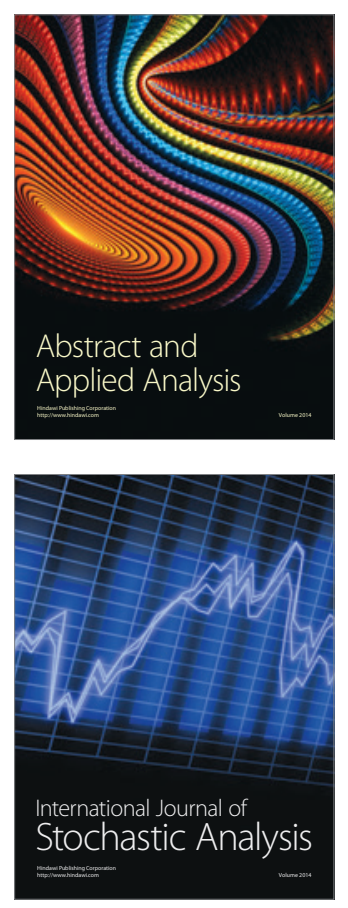

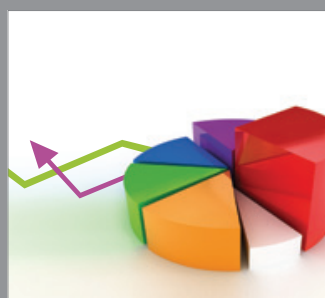

ournal of

Probability and Statistics

Promensencen
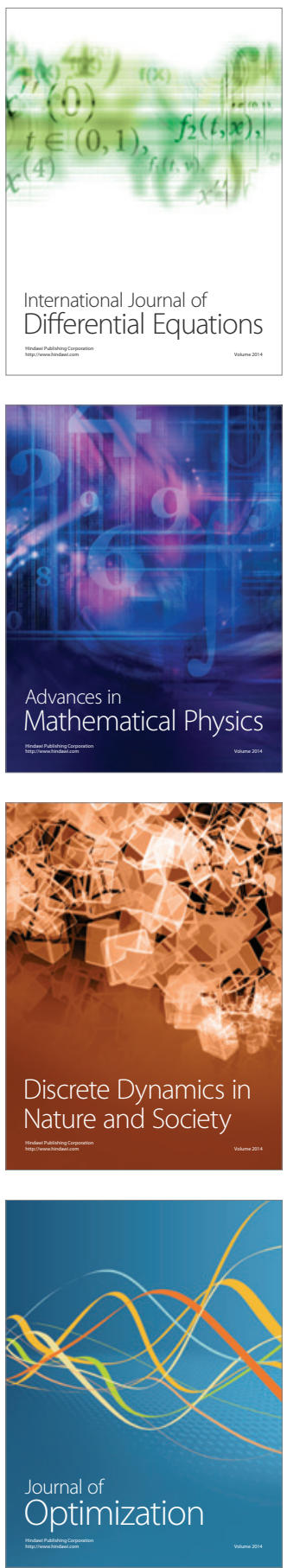